\title{
LOS BLOGS DENTRO DEL TURISMO 2.0
}

\author{
Juan Marcos Filgueira Gomis \\ Consellería de Educación e Ordenación Universitaria, Xunta de Galicia
}

\begin{abstract}
Resumen:
Las nuevas tecnologías aparecidas con la Web 2.0 tienen su aplicación en el mundo del turismo y los viajes dando lugar al denominado Turismo 2.0 del que los blogs son un elemento fundamental. Los blogs suponen una innovación en las estrategias de marketing para empresas e instituciones que ofertan servicios turísticos del mismo modo que representan un nuevo conjunto de herramientas para los usuarios de dichos servicios. Estas posibilidades y herramientas se plasman con diferentes formas dentro de la Blogosfera.
\end{abstract}

Palabras clave: Web 2.0, Turismo 2.0, blogs, marketing, Blogosfera.

Resumo: Os blogs dentro do turismo 2.0

As novas tecnoloxías aparecidas coa Web 2.0 teñen a súa aplicación no mundo do turismo e as viaxes: velaí xorde o denominado Turismo 2.0, de que os blogs son un elemento fundamental. Os blogs supoñen unha innovación nas estratexias de mercadotecnia para empresas e institucións que ofrecen servizos turísticos e, do mesmo modo, representan un novo conxunto de ferramentas para os usuarios dos devanditos servizos. Estas posibilidades e ferramentas plásmanse con diferentes formas dentro da blogosfera.

Palabras clave: Web 2.0, Turismo 2.0, blogs, mercadotecnia, blogosfera.

\begin{abstract}
Blogs within Travel 2.0
The new technologies which arose with Web 2.0 have an application in the world of travel and tourism, and have led to the so-called Travel 2.0, in which blogs are an essential element. Blogs represent an innovation in marketing strategies for companies and institutions offering tourism services, as well as a new set of tools for users of those services. These possibilities and tools materialise in different ways within the Blogosphere.
\end{abstract}

Key words: Web 2.0, Travel 2.0, blogs, marketing, Blogosphere.

\section{TURISMO 2.0}

Internet crece día a día, ofreciendo nuevas herramientas y posibilidades. En los últimos años el crecimiento ha sido tan importante que se ha comenzado a hablar de la finalización de una revolución o período evolutivo que da lugar a una nueva Web, denominada por muchos la Web 2.0, una innovación dentro de la Red. 
La Web 2.0 representa un conjunto de herramientas y servicios que posibilitan nuevos niveles de comunicación, acceso, publicación y recuperación de información. Según O’Reilly (2005), principal promotor de la concepción de una Web 2.0, ésta se encuentra constituida por siete pilares básicos: la World Wide Web como plataforma de trabajo, el fortalecimiento de la inteligencia o memoria colectivas, la primordial gestión de las bases de datos, el fin del ciclo de las actualizaciones de versiones del software, la búsqueda de la simplicidad, el software enfocado a la portabilidad y las experiencias enriquecedoras de los usuarios. Partiendo de esta concepción, la estructura taxonómica que permite establecer una clasificación dentro del modelo Web 2.0 se fundamenta según Cobo y Pardo (2007) en cuatro líneas fundamentales: Redes Sociales (Social Networking), Contenidos, Organización Social e Inteligente de la Información y Aplicaciones y Servicios (Mashups).

I las Redes Sociales agrupan aquellas herramientas e ideas utilizadas para crear o facilitar comunidades virtuales que permitan comunicarse y compartir información;

I Contenidos abarca todas aquellas herramientas que facilitan la publicación y el acceso a los contenidos web, tales como blogs, sistemas de gestión de contenidos ${ }^{1}$ o wikis

I la Organización Social e Inteligente de la Información, agrupa aquellas que permiten clasificar, ordenar, indexar, estructurar y recuperar eficientemente dentro de la gran masa de información proporcionada. Se trata de buscadores, directorios, sistemas para subscribirse a contenidos y marcadores sociales ${ }^{3}$;

I por último, dentro de la línea de Aplicaciones y Servicios vendrían todas aquellas herramientas, softwares, plataformas y recursos que, no teniendo cabida en las categorías anteriores, ofrecen nuevos servicios a los usuarios finales como escritorios y almacenamiento virtuales entre muchos otros.

La Web 2.0 funciona a modo de amalgama de todas estas aplicaciones y servicios web de forma que se combinan y colaboran entre sí permaneciendo además en constante evolución, por lo que la clasificación debe basarse en fundamentos o conceptos generales ante la imposibilidad de hacerlo en elementos concretos.

La innovación que supone esta Web 2.0 aplicada al mundo del turismo y los viajes da como resultado el modelo de Turismo 2.0 (Travel 2.0). Se trata de un nuevo modelo de Internet para consultar, publicar, compartir, discutir y distribuir información sobre turismo cuyo contenido sea creado por los usuarios interactuando entre ellos. Debido a su enorme difusión a escala mundial, se posibilita su utilización dentro de estrategias de marketing a través de la red para destinos turísticos. Cualquier persona en cualquier parte

1 También llamados CMS (Content Management System): permiten la creación y administración de contenidos y estructuras en páginas web.

2 Wiki: Sitio web colaborativo donde el contenido es elaborado por una comunidad de autores. Se basa en la definición de conceptos relacionados mediante enlaces de hipertexto.

3 Sistemas de compartir y clasificar enlaces en base a marcadores que los definen y que asignan los usuarios del sistema. Un ejemplo es Del.icio.us: http://del.icio.us. 
del mundo podrá consultar y expresar sus ideas y experiencias sobre un destino turístico y compartirlas con el resto del mundo a través de Internet, dejando abierta la posibilidad de que otras personas aporten a su vez nueva información originando una plataforma colaborativa de construcción de conocimiento compartido y distribuido funcionando a modo de red social.

Para autores como William (2007) -partiendo de la definición de O’Reilly para Web 2.0- el modelo de Turismo 2.0 se definiría como "la revolución empresarial en la industria del ocio y el turismo causada por el traslado hacia un ecosistema como plataforma, y una tentativa para comprender las reglas del éxito de ese nuevo ecosistema. La principal entre esas reglas es construir destinos y empresas que impulsen los efectos de las redes para conseguir que mejore su productividad en cuanto más gente participa en ellas. Es decir, por el impulso de la inteligencia colectiva".

Figura 1. Modelo de comunicación tradicional frente al Modelo Web 2.0.

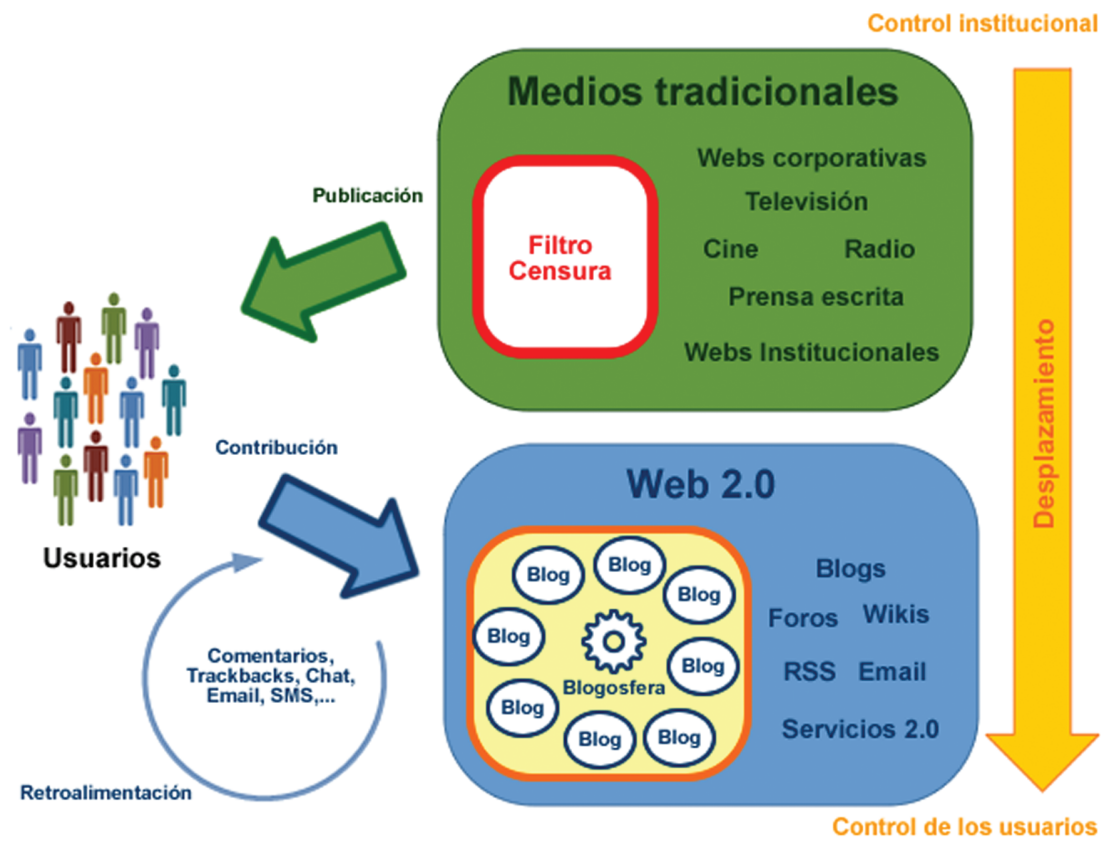

Fuente: Elaboración propia.

La Web 2.0 ha supuesto un cambio en el acceso de las personas a la información. Frente a la anterior perspectiva donde los medios tradicionales monopolizan la información a través de radio, prensa, televisión y páginas web institucionales o propiedad de 
los medios de comunicación aparece un nuevo modelo donde, un amplio conjunto de individuos ofrece el punto de vista particular de cada uno originando redes sociales de conocimiento. Estas redes sociales de comunicación individual para muchos suponen un desafío y una verdadera alternativa a los medios de comunicación de masas tradicionales y este cambio ha quedado de manifiesto en multitud de aspectos. Empezando por el periodismo, al aparecer noticias y artículos de opinión incluso con fotografías captadas utilizando teléfonos móviles que escapan a cualquier forma de control de los medios de comunicación de masas tradicionales. Algunos de los ejemplos más famosos serían el periodismo alternativo sobre la Guerra de Irak, sobre atentados terroristas ocurridos en cualquier parte del mundo, sobre los polémicos comicios electorales del año 2004 en EEUU o la "revolución naranja" de Ucrania.

Figura 2. Estadísticas de actividad de Technorati identificando noticias puntuales.

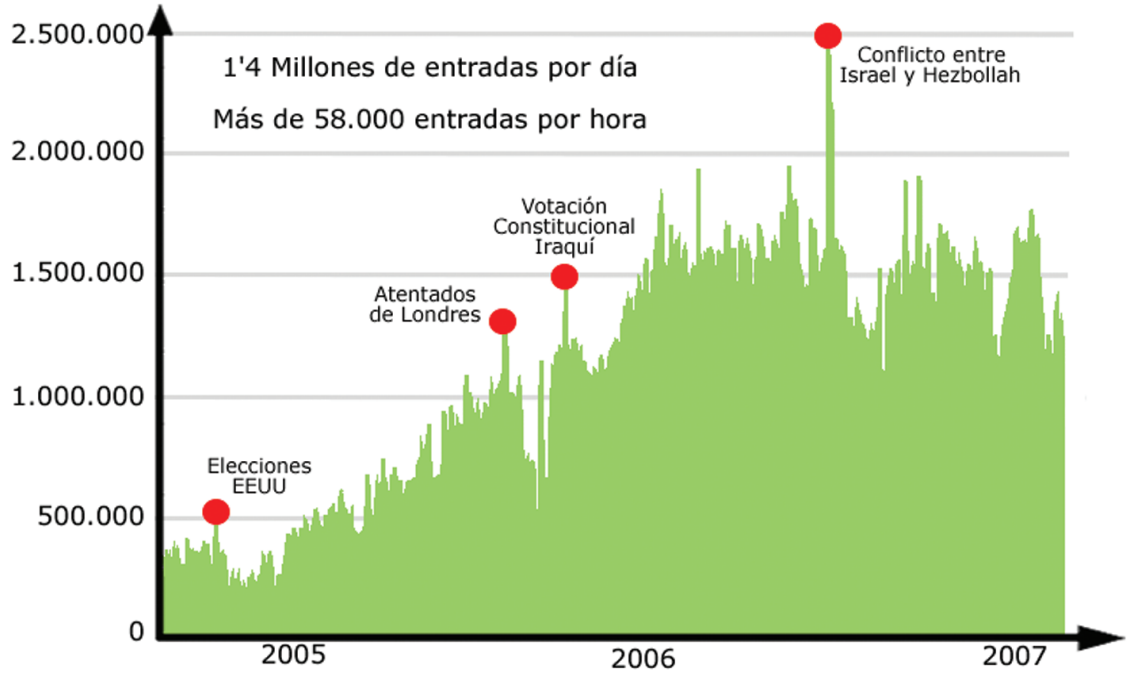

Fuente: Technorati.

Desde nuestro punto de vista, para el caso del turismo podemos ver una analogía con el periodismo en el sentido de que, hasta ahora, la información turística se encontraba, en gran medida, monopolizada por grandes empresas, organismos institucionales y agencias de viajes, del mismo modo que los medios de comunicación de masas tradicionales hacían con el periodismo. Ocurre actualmente un fenómeno de aparición de nuevas formas de comunicación de información donde cada usuario o turista particular tiene 
la posibilidad de ofrecer su propio punto vista y experiencia acerca de un destino concreto participando como medio de comunicación individual. Los usuarios que consulten Internet para saber más acerca de su destino turístico pueden obtener información de primera mano acerca del mismo elaborada por otros usuarios en sus mismas condiciones, valoración de alojamientos y servicios, recomendaciones, alerta de abusos o engaños, vídeos, fotografías o cualquier experiencia vivida. Toda esta información se encuentra al margen de cualquier tipo de censura que podría darse por intereses económicos cuando se habla de medios de comunicación de masas propiedad de grandes empresas o instituciones. Si en el modelo anterior que podríamos denominar Turismo 1.0, la información sobre turismo obtenida a través de la Web venía de páginas propiedad de los propios establecimientos o instituciones, en el modelo Turismo 2.0 dicha información se completará con la proporcionada por otros usuarios que ya han utilizado dichos servicios y que escriben libremente sobre ellos.

\section{BLOGS Y TURISMO}

Como se ha mencionado anteriormente, el Turismo 2.0 tiene a su disposición todas las herramientas que vienen de la mano de la Web 2.0. Como buque insignia de todas ellas debido a su función de eje central y enorme difusión se encuentran los blogs. El término blog proviene de la palabra inglesa weblog, que viene a significar diario web. A continuación vinieron otros nombres: diarios personales on-line, cuaderno de bitácora o bitácora a secas, términos que acostumbran emplearse a modo de sinónimos. Originalmente fueron ideados como páginas web personales donde se iban publicando entradas por orden cronológico inverso funcionando a modo de diario. Debido a su enorme evolución podemos decir que hoy en día se trata de páginas web con cualquier orientación o propósito y tanto este orden cronológico como el concepto de diario personal pasaron a un segundo plano. Su principal característica es su concepción como herramienta de publicación de contenidos multimedia, de manera que cualquier persona que posea unos conocimientos mínimos de informática a nivel de usuario puede utilizarlos para crear una página web y publicar lo que desee en cuestión de minutos. Existe un gran número de proveedores gratuitos, tanto de la herramienta de publicación como del alojamiento web, por lo que el coste de disponer de una página web se limita al derivado de disponer de un ordenador con conexión a Internet. La evolución desde sus inicios como diarios personales ha sido tal que se ha permitido: variar el orden de las entradas, incluir páginas estáticas accesibles desde menús, establecer jerarquías de usuarios para publicación y administración, añadir funciones de archivo de entradas por fecha, palabras clave y clasificación por categorías $^{4}$. Además, en cuanto a su contenido pueden contemplar cualquier tipo de temática. Los que en su día fueron unos sencillos diarios personales se han convertido en auténticos portales que día a día aumentan con nuevas funcionalidades. Ya no se trata

\footnotetext{
4 Relación de secciones o temas en que se organizan las entradas de un blog.
} 
de una simple página web, sino que se trata de potentes herramientas de gestión de contenidos gratuitas de las que se puede disponer al instante.

Figura 3. Blogs registrados por Technorati.

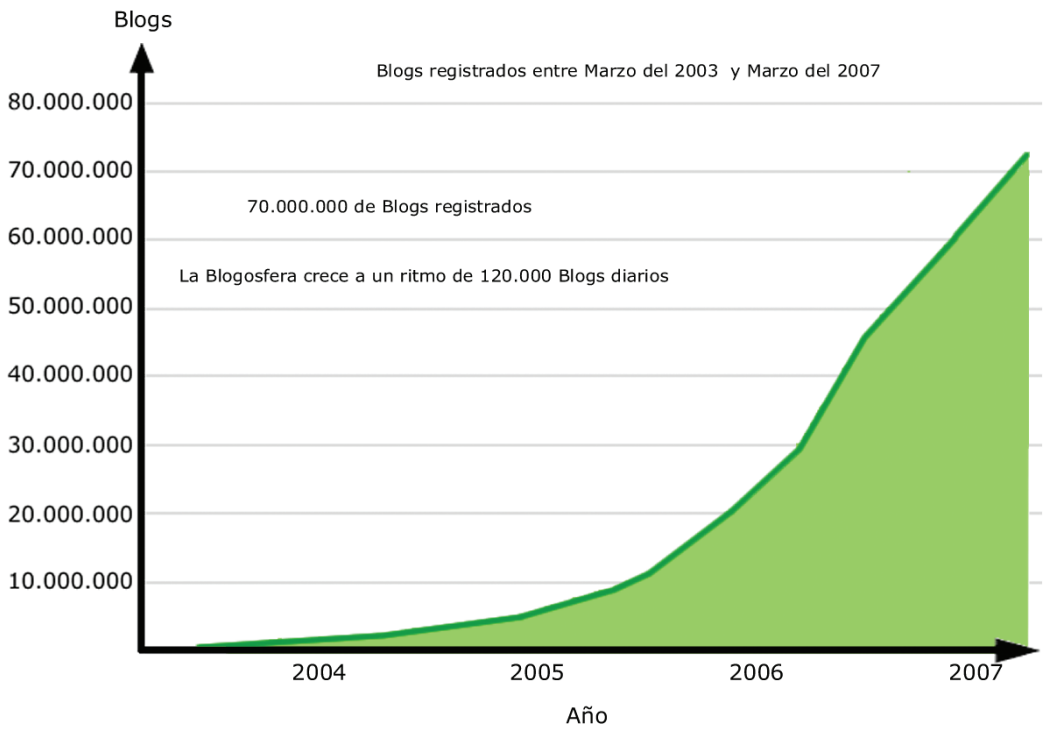

Fuente: Technorati.

El fenómeno de los blogs ha experimentado un enorme crecimiento cuantitativo en los últimos dos años. Technorati, reconocido buscador de blogs a escala mundial, tenía registrados en marzo del 2007 cerca de setenta millones. Estos blogs conforman la Blogosfera, el submundo o universo de los blogs. Manteniendo un ritmo de crecimiento donde el número total de blogs se dobla en tamaño prácticamente cada seis meses (véase figura 3). Cada blog representa una página o sitio web, que puede ser resultado de una consulta en un buscador, pero para determinar qué porcentaje del número total de blogs podemos considerar que están relacionados con el turismo se debe buscar una posible clasificación temática de los mismos para tratar de obtener una idea aproximada de ese número. Technorati no ofrece una clasificación temática de los blogs que tiene registrados. A nivel global, es difícil realizar un estudio automático sobre el tema principal de un conjunto de blogs, ya que -entre otros aspectos- un mismo blog puede tratar un gran número de temáticas, tantas como le apetezca a su autor, de manera conjunta sin especializarse en ninguna en concreto. Podemos hablar de blogs especializados en Viajes o 
Turismo, pero también de blogs como diarios personales, donde sus autores pueden reflejar de manera puntual sus vacaciones o viajes.

De todas formas, a modo de aproximación, un estudio reciente del Grupo de Novos Medios de la Universidad de Santiago de Compostela (2006), a partir de una muestra de 320 bitácoras gallegas, ha realizado una clasificación temática que puede ser tomada como referencia. Al tratarse de un espectro lo suficientemente reducido, puede realizarse una comprobación manual sobre cada bitácora para establecer la estadística.

Figura 4. Clasificación temática de las bitácoras gallegas.

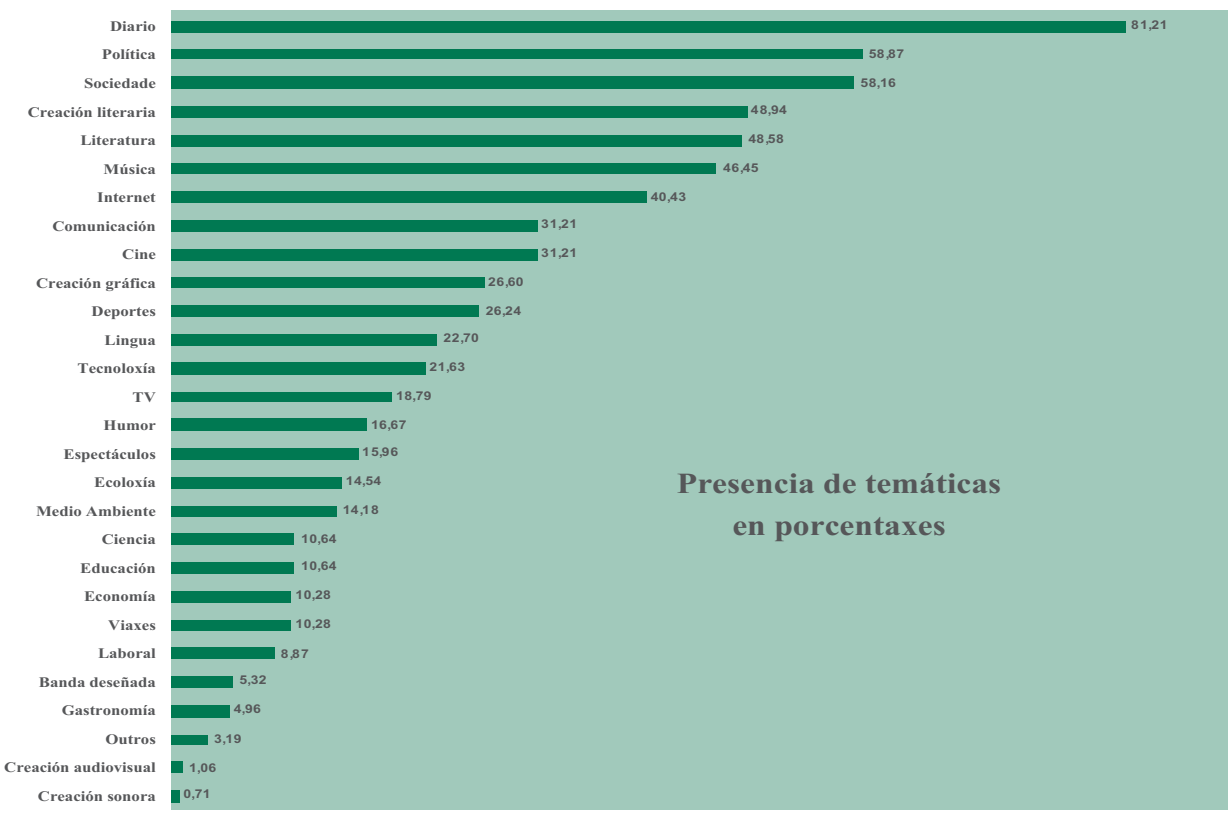

Fuente: Novos Medios (2006).

De este modo vemos que el porcentaje de blogs con la presencia del tema Viajes aparece con un significativo $10.28 \%$ dentro del total y extrapolándola a la cifra total de blogs vista anteriormente podemos estimar una cifra realmente considerable de blogs dedicados a Viajes a efectos de representar un factor a tener en cuenta dentro de la industria del turismo y como ámbito de actuación para posibles estrategias de marketing.

\section{POSIBILIDADES DE LOS BLOGS}

A continuación se verán algunas posibilidades que ofrecen los blogs como base del Turismo 2.0. La influencia de éste, según William (2007), "hace referencia al sector turístico en su totalidad, por lo que se deben considerar todos los elementos de su cade- 
na de valor. El objetivo es la mejora de la productividad -aportada por el conocimientode las empresas y destinos". Es decir, se debe considerar que el Turismo 2.0 afecta tanto a las instituciones y grandes y pequeñas empresas de la industria del turismo como a los usuarios o clientes que utilizan sus servicios.

I Para las primeras aparece como una nueva estrategia de marketing a través de la red. Permite publicitar los productos con las últimas herramientas del mercado, interactuando con las redes sociales y comunidades de usuarios y mejorando su competitividad.

I Para los clientes permite obtener valoraciones y opiniones de primera mano de otros usuarios en sus mismas condiciones además de conseguir una información mucho más completa del destino, por tener las aportaciones tanto escritas como en imágenes o vídeo en un mayor número.

Si las empresas e instituciones desestiman este campo corren el riesgo de que a los usuarios sólo se les muestre una visión negativa o incompleta de sus productos, pudiendo darse la indeseada situación de que su imagen quede reducida a usuarios descontentos o críticas agresivas fruto de la competencia desleal. Puestos a querer vender un producto deben publicitarlo con las mejores herramientas y por todos los medios posibles, así como buscar valoraciones y recomendaciones positivas de los propios usuarios. Tanto para buscar nuevas estrategias de marketing de su producto como para enfrentarse al riesgo de una publicidad negativa el interactuar con los usuarios en su terreno debe ser uno de los objetivos de empresas e instituciones dedicadas a la oferta de productos turísticos. El modo de promoción de las valoraciones y opiniones en Internet es similar al de cualquier fenómeno de boca a boca al uso con la salvedad de que publicar un contenido en Internet supone hacerlo siempre a una escala mundial, permitiendo acceder a él a cualquier persona con acceso a la red, en cualquier parte del mundo.

Este peso o importancia de la publicación se acentúa en gran medida en los blogs, ya que llevan asociados, en muchas ocasiones de manera incluso implícita, su asociación con otros blogs, directorios de blogs y buscadores. Cuando obtenemos un blog, éste se da de alta automáticamente en multitud de servicios que facilitan a los usuarios la búsqueda de información, tarea que debía hacerse manualmente en las páginas web englobadas dentro del modelo Web 1.0, realizando todo el proceso de promoción web sin coste alguno. Éste es quizá uno de los principales aspectos de la importancia y difusión de los blogs, por representar una gran ventaja sobre las páginas del modelo Web 1.0. Una ventaja en dos sentidos: a la hora de publicar la información y a la hora de recuperarla o acceder a ella. La información publicada en los blogs puede encontrarse o recuperarse atendiendo a los criterios de búsqueda de los usuarios de una manera mucho más eficiente. A partir de cualquier información recuperada, generalmente a modo de entrada de blog, se permitirá siempre la fácil interacción con otros usuarios a través de la publicación de comentarios o valoraciones. De esta forma, se sociabiliza la publicación al permitir que nuevos usuarios aporten nueva información y puedan sugerir enlaces a entradas de sus propios blogs para crear redes sociales de información generando conocimiento colectivo y distribuido sobre el tema a tratar. Como en su propio blog pueden 
mostrar referencias a la entrada o entradas originales, denominadas trackbacks ${ }^{5}$, se facilita además la navegación en el sentido original cerrando el círculo de información. Con este sencillo sistema de comentarios, valoraciones, enlaces y trackbacks se facilita enormemente la circulación de información permitiendo que se propague a través de otros blogs para establecer la red de conocimiento social distribuido.

Por lo tanto, dentro de las posibilidades que ofrecen los blogs para los usuarios de la industria del turismo se encuentran: la publicación y promoción de información, la búsqueda y recuperación centrada en criterios de búsqueda de la propia información, la posibilidad de interactuar con otros usuarios a través de la función siempre directa de comentarios y opiniones, así como la facilidad en el movimiento y circulación de la información a través de la red. Ya que el modelo de los blogs es la base a seguir por la mayoría de herramientas de la Web 2.0, que siguen el mismo modelo de publicación aunque variando en los contenidos, podemos decir además que estas posibilidades son extrapolables a otras herramientas del Turismo 2.0.

Para la otra cara de la moneda, es decir, las empresas e instituciones que ofertan los productos turísticos, los blogs suponen una innovación en la forma de realizar publicidad on-line. Permiten exponer información de una manera clara a través de un medio adaptado a las últimas tecnologías y que se actualiza automáticamente. Lo ideal sería presentar la información del producto en el blog de una manera sencilla y enfocada hacia el usuario teniendo en cuenta sus posibles criterios de búsqueda. Tanto dentro de las características de los blogs como en la de sus directorios y buscadores especializados se admiten clasificaciones de la información basadas en una categoría o clasificación general y una representación del contenido utilizando etiquetas o $\operatorname{tags}^{6}$. Estos elementos funcionan a modo de marcadores de la información y facilitan que el contenido sea recuperado por los usuarios en sus consultas. En una web que utiliza los estándares del modelo Web 1.0, la promoción de la web o alta en buscadores sería manual y la definición del peso para mostrar los resultados de una búsqueda quedaría a criterio del buscador. Con los blogs, se permite hacer énfasis en términos de diversos marcadores de su contenido y en las valoraciones de los usuarios gracias a herramientas específicas del modelo Web 2.0, con lo que resulta más fácil para un usuario obtener aquella información que desea, pero para que el producto ofertado se encuentre en ella debe cumplir las premisas básicas del modelo.

Por otra parte, otra de las características del modelo, la socialización, por estar centrado en el usuario, abre el camino a un posible sistema de marketing por dos vías: correo electrónico y sindicación de contenidos. Para el primero nos permite la captación de dichos usuarios como miembros del blog, lo cual -con el consiguiente permiso- posibilita el mantenimiento de listas de correo para el envío de novedades y ofertas. Para el

5 Trackback: Enlace inverso entre blogs que permite enlazar una entrada con otras páginas o blogs que la citan o referencian.

6 Por etiquetas o tags se conoce al conjunto de palabras clave que representan o describen un contenido más amplio, y que se utilizan como marcadores de esa información. 
segundo, da la posibilidad al usuario de suscribirse a los sistemas de sindicación de contenidos $^{7}$. La suscripción permite al usuario obtener de forma automática a través de lectores de sindicación de contenidos las nuevas entradas de blogs, y por tanto mantenerse informado de manera similar al caso del correo electrónico de las entradas conteniendo las novedades y ofertas que publiquemos.

Una nueva posibilidad, que aunque difícil de controlar puede ser la que mayores beneficios aporte a la publicidad del producto, es el Social Media Marketing o marketing basado en la utilización de las redes sociales como medio de propagación de contenidos y mensajes a través de técnicas virales ${ }^{8}$. Un ejemplo exitoso de esta técnica aplicada al turismo sería el de una reciente campaña donde una compañía aérea ofrecía vuelos a Londres a un precio casi simbólico (tasas aparte). Al tratarse de una oferta tan impactante, los usuarios reenviaban la publicidad a su red social, completándose el proceso con la visita a la página web de la compañía para profundizar en la información. Dentro de los blogs, el sistema de comentarios, enlaces y trackbacks tiene un funcionamiento análogo, de modo que una entrada puede propagarse de modo similar a un correo electrónico viral. Este sistema, que en esencia no es más que el típico boca a boca tan influyente en publicidad, puede utilizarse de manera beneficiosa para mejorar la imagen de un producto siempre y cuando se deje abierta la posibilidad utilizando los medios de que disponen los blogs. Se puede buscar, y se debe permitir, que los usuarios puedan valorar el producto. Si el producto es de calidad, las valoraciones positivas de usuarios son la mejor publicidad para aumentar la fiabilidad y confianza del mismo. Si el producto no es de calidad o las críticas no son favorables, permite ver el punto de vista real de usuarios que han catado el producto y realizar cambios para corregir la situación. Debido a la facilidad de circulación de información en los blogs y la facilidad de expresar sus opiniones y valoraciones por parte de los usuarios utilizando estas herramientas, está claro que como estrategia de marketing, tanto para la industria del turismo como para cualquier otra, ésta será siempre un arma de doble filo. En el caso de encontrarse ante una situación contraria, la solución pasaría por aceptar las críticas e intentar mejorar la oferta o el producto. Autores como Carpintier (2003) se hacen eco de este aspecto: "Pocas empresas están preparadas para contrarrestar una corriente adversa en Internet. Muchas ni llegan a conocerlas. La repercusión de las opiniones vertidas en medio centenar de comunidades con miles de clientes (o incluso cientos de miles) sobre un producto o servicio de una compañía cualquiera puede no ser inmediata, pero tiene gran calado a medio plazo. Las empresas lo olvidan bajo su responsabilidad. ... ¿Dónde sino en Internet podemos acceder, de forma gratuita y voluntaria, a miles de clientes que hablan, opinan e intercambian impresiones sobre nuestros productos?”. Asociado a este tipo de

7 La sindicación de contenidos se realiza publicando el contenido del blog en archivos XML utilizando formatos específicos como RSS (Really Simple Sindication) o Atom.

8 El término viral proviene del mecanismo de propagación de determinados virus a través de redes sociales, de modo que son los propios usuarios, voluntariamente, quienes reenvían a toda o gran parte de su libreta de direcciones un contenido que consideran interesante, consiguiendo que de esta forma se propague de modo exponencial a infinidad de usuarios. 
marketing ha surgido en las grandes empresas, generalmente grandes hoteles o cadenas hoteleras una figura centrada en este tipo de marketing, se trata del Social Media Optimizer ${ }^{9}$. El hecho de disponer de una figura con dedicación plena da muestras de la sensibilidad de las empresas hacia este factor. Para algunos autores como Celaya y Herrera (2007) uno de los principales objetivos de esta figura debe ser el identificar a los líderes de opinión o tecnoinfluenciadores ${ }^{10}$ que en los Estados Unidos llegan a un número de 11 millones, y cuya influencia se estima en un ámbito de actuación cercano a los 155 millones de consumidores. Según datos del año 2005, de la consultoría de comunicación norteamericana Burson-Marsteller, que publicó un estudio sobre la forma en que los tecnoinfluenciadores transmiten y crean opinión, aparece el poseer y publicar entradas en un blog propio con un significativo 33\% (véase figura 5).

Figura 5. Porcentaje de medios de transmisión de información empleados por los tecnoinfluenciadores.

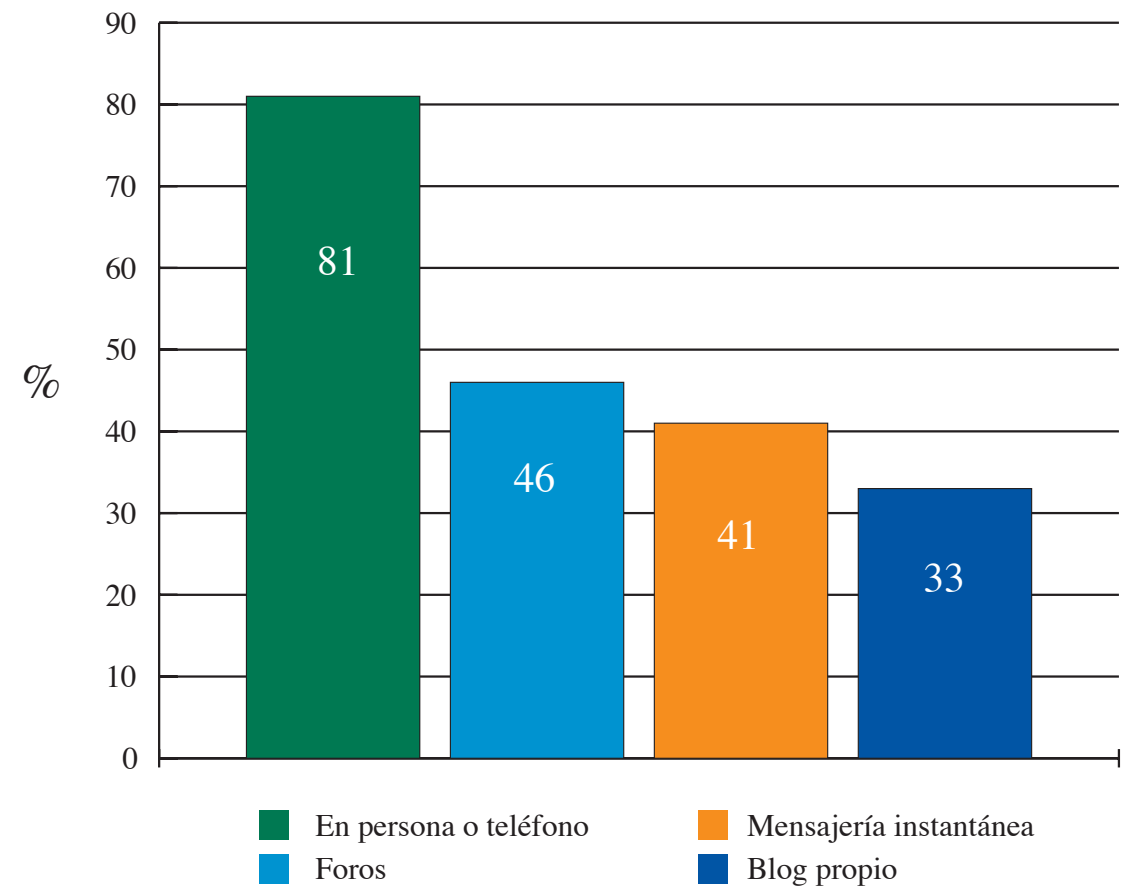

Fuente: Consultoría Burson-Marsteller, tomado de Celaya y Herrera (2007).

9 También conocido como Community Manager, profesional dedicado al estudio y publicidad dentro de redes sociales, encargándose de todo lo relacionado con el Social Media Marketing.

10 Personas que utilizando las últimas tecnologías son capaces de transformar comportamientos de compra de grupos de usuarios mediante la publicación de recomendaciones y opiniones. 
Se echa en falta dentro de la comparativa el porcentaje de comentarios publicados en otros blogs así como en páginas web corporativas, lo cual completaría la actividad de estos líderes de opinión dentro de la Red. Este dato, sí aparece reflejado en el estudio de Forrester (2007), aunque en este caso el estudio se amplía a la totalidad de consumidores on-line adultos en Estados Unidos y su actividad dentro del mundo de los blogs. El estudio realiza una clasificación de los usuarios según sea su nivel de actividad, poseer un blog propio, comentar en blogs, o dedicarse sólo a su lectura, entre otros. Se muestra una escala con los resultados obtenidos donde se agrupa a los usuarios en segmentos según dicho nivel de actividad o participación (véase figura 6). El primer estudio da una idea del papel que los blogs representan con relación al factor de los tecnoinfluenciadores mientras que el segundo estudio muestra su influencia dentro de la totalidad de consumidores on-line. Ambos factores deberían ser por extensión objetivos donde enfocar el Social Media Marketing.

Figura 6: Consumidores on-line adultos en Estados Unidos según su actividad en la Blogosfera.
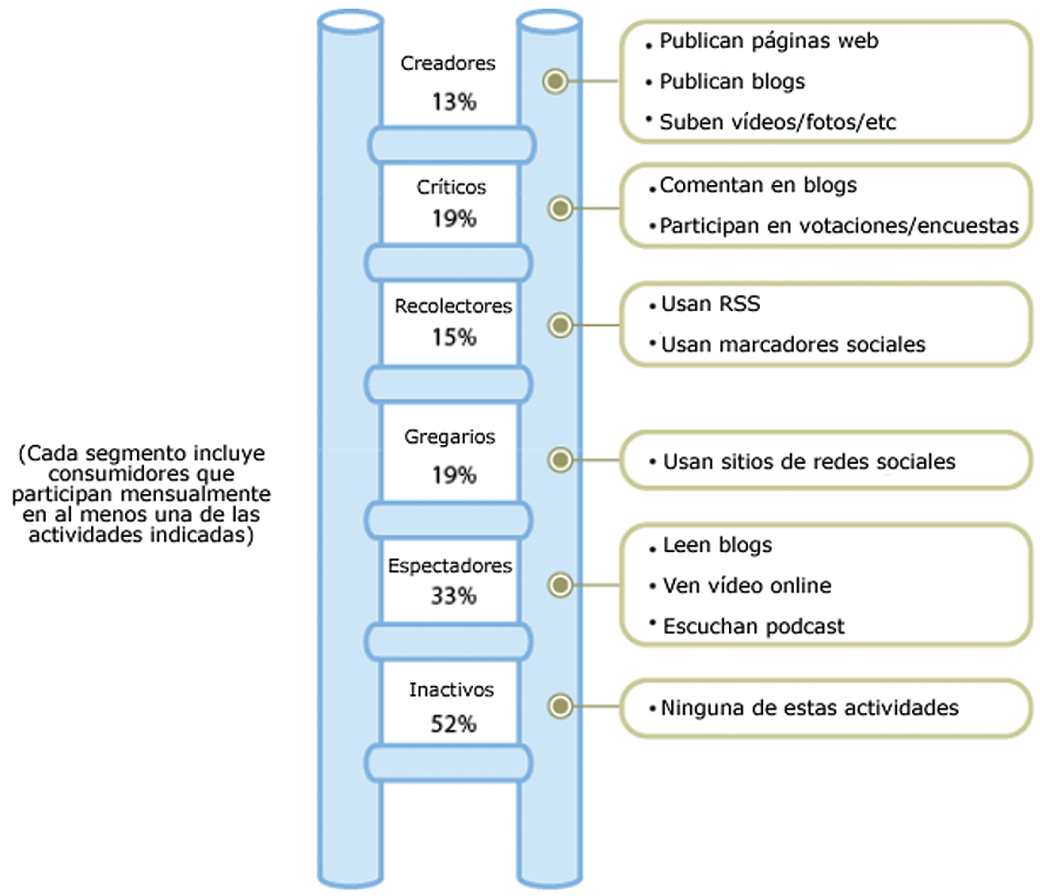

Fuente: Forrester report on Social Technographics (2007).

Por último, no hay que olvidar que el acceso a estas redes sociales y la interacción de primera mano con los usuarios representan una fuente de información u origen de 
datos para el estudio de la opinión de los usuarios, tanto de nuestro producto como de otros productos de la competencia. La recopilación de opiniones, valoraciones y comentarios pueden representarse a modo de factores a partir de los cuales los usuarios se aceptan o rechazan un producto o se inclinan por el que ofrece otro proveedor. Celaya (2006), comparte la opinión de que el fenómeno blog supone una nueva fuente de información para ser analizada por expertos en comunicación. Complementariamente, la interacción directa con los usuarios permite ampliar los resultados de cuantificación sobre dichos factores, tanto a través de los mecanismos de interacción ya mencionados como con la propuesta de encuestas o votaciones cuya inclusión en los blogs se realiza de manera directa ya que la mayoría contemplan por defecto estas extensiones. El análisis de estos estudios puede marcar el camino a seguir por el resto de estrategias de marketing para obtener una mayor aceptación por parte de los usuarios.

En resumen, para las instituciones y empresas que ofertan productos turísticos, las posibilidades de los blogs se centran en la mejora de las estrategias de marketing y publicidad on-line atendiendo a cuatro líneas fundamentales:

I La publicidad on-line del producto en sí utilizando las últimas herramientas tecnológicas y haciendo especial hincapié en la optimización del proceso de recuperación de información.

I Estrategias de marketing basadas en la captación y suscripción de usuarios al servicio para mantenerlos informados de novedades y ofertas a través de listas de correo y sindicación de contenidos.

I El Social Media Marketing que se consigue al hacer uso de las redes sociales para promocionar el producto a través de la red basándose en la fiabilidad y confianza del mismo.

I Origen de datos para estudio y evaluación de usuarios, tanto propios como de la competencia. Permite obtener información o interactuar con los usuarios de primera mano para determinar porqué eligen o descartan un producto.

\section{ORGANISMOS DE LA BLOGOSFERA}

La Blogosfera es el ecosistema o universo donde conviven los blogs. La subred dentro de Internet donde se engloban todos los sitios, herramientas y servicios web relacionados con los blogs. A continuación se enumeran distintos organismos que habitan en la misma, o dicho de otro modo, clasificaciones de los blogs por su modo de funcionamiento, centrándonos en aquellos que guardan relación con el mundo del turismo y los viajes. Todos los blogs guardan similitudes en cuanto a su estructura y modo de funcionamiento por lo que la clasificación se realizará en cuanto a su propósito, temática y funcionalidad. Lew (2007), realiza una clasificación centrada en la perspectiva del usuario, diferenciando tres tipos de bitácoras de viaje: diarios de viaje personales, noticias y opiniones sobre turismo y blogs de destinos. Esta clasificación resulta demasiado básica para un sistema del tamaño y alcance del Turismo 2.0 dentro de la Blogosfera por lo que creo necesario ampliarla. Partiendo de un enfoque análogo al apartado anterior, la primera clasificación 
que podemos realizar es basándonos en la autoría del blog, dependiendo de si se trata de empresas o instituciones que ofertan servicios, usuarios de dichos servicios o herramientas genéricas que ayudan a unos y otros a realizar funciones dentro del sistema.

1. Empresas e instituciones. Dans define el blog corporativo como "un blog publicado por o con el soporte de una organización, con el fin de contribuir a que alcance sus objetivos corporativos. De cara a la comunicación externa, los objetivos pueden incluir la comunicación y establecimiento de relaciones con clientes, medios de comunicación u otros grupos objetivo, el posicionamiento de la organización o de ciertos individuos pertenecientes a ella como expertos en campos de actividad de la industria a la que la organización pertenece, la optimización del posicionamiento en buscadores de Internet, el reclutamiento de personal, la realización de test o pruebas de productos o conceptos, etc" (Dans, 2005). Podemos tratar de proveer a nuestra empresa o institución de cualquiera de estas posibilidades mencionadas en función de nuestras necesidades, pero en cualquier caso, dado que siempre se oferta un producto o servicio, su objetivo principal será publicitarlo. Para ello se puede optar por utilizar bitácoras que oferten un único producto o de manera conjunta varios productos relacionados. El formato de blog por su orden cronológico de entradas se adapta perfectamente al de un sistema de noticias donde registrar las ofertas y novedades que van apareciendo ordenadas por su fecha de aparición. La posibilidad de páginas estáticas permite presentar el producto de manera clara y en detalle utilizando cualquier tipo de contenido multimedia que se desee. Si una imagen vale más que mil palabras, un vídeo es un gran número de imágenes con sonido y, tratando con blogs, se pueden incluir otros elementos derivados de la utilización de herramientas propias del modelo Web 2.0: sistemas de localización geográfica, representación de paisajes en galerías de $360^{\circ}$, enlaces a sistemas de reservas on-line, etc... Gracias a las cada vez más precisas y completas herramientas, cada día obtenemos representaciones de los productos más tangibles a través de Internet. Los principales ejemplos de iniciativas de blogs corporativos las encontramos en el ámbito hotelero ${ }^{11}$, algunas de ellas invitan a los usuarios a realizar valoraciones sobre sus servicios dentro del propio blog en una aplicación directa de Social Media Marketing. Junto a estas bitácoras coexisten otras, grupales o comunitarias, las cuales tienen como autores a comunidades de proveedores de la misma localidad o zona turística que aúnan esfuerzos para promover una determinada zona o ruta turística ya que el beneficio será común. Un ejemplo de este tipo de bitácora grupal sería una comunidad de hosteleros ubicada en la zona vieja de una gran ciudad que dan a conocer sus establecimientos de manera conjunta proponiendo una posible ruta turística. Como ejemplos de casos de éxito de estas iniciativas se pueden mencionar asociaciones de turismo rural ${ }^{12}$, de balnearios y spa $^{13}$ o de restaurantes ${ }^{14}$.

11 P. ej. Experiencias NN (Núñez i Navarro): http://experienciasnn.com; Eurostars Hotels: http://blog.eurostarshotels.com; Hoteles Monte: http://blog.hotelesmonte.com.

12 P. ej. Club rural: http://clubrural.com; Escapada rural: http://escapadarural.com; Descubre rural: http://descubrerural.com.

13 P. ej. Balnearios-Spa: http://balnearios-spa.blogspot.com.

14 P. ej. Club restaurantes: http://www.clubrestaurantes.com. 
2. Usuarios. Desde el punto de vista de los usuarios, nos encontramos una variedad mucho más rica de apariciones en bitácoras. Empezando con todo tipo de entradas sueltas en diarios personales de carácter general. Si alguien desea narrar al mundo su vida, también narra sus viajes y desde el punto de vista anecdotario, es más fácil que encuentre algo que contar en un viaje que en la vida cotidiana. Este tipo de bitácoras pueden incluir fotografías o vídeo y estar cargados de valoraciones y opiniones, dando pie a nuevos comentarios y opiniones por parte de los lectores de su blog. Frente a estas bitácoras de temática abierta aparecen las que están especializadas en los temas de turismo o viajes. Dentro de ellas encontramos los diarios de viaje, auténticos cuadernos de bitácora empleados para el mismo fin que aquellos que les dan nombre, que permiten al viajero mantener registro de su viaje desde cualquier ordenador en cualquier país, en cualquier parte del mundo, transmitiendo dicho registro al mundo, o por lo menos a su familia y amigos preocupados por sus andanzas. Periódicamente se amplía el registro incorporando nueva información con imágenes o vídeo. En otro grupo, encontramos blogs sobre destinos o lugares, se trata de bitácoras que recopilan información sobre un determinado lugar, destino o ruta turística. Aquí encontramos autores que quieren dar a conocer una determinada localidad o que habiendo viajado a un determinado lugar deciden publicar el conocimiento que han obtenido en Internet. El rigor de la información publicada depende siempre del autor pero para algunos destinos ésta puede resultar la única o la más completa fuente de información a través de Internet. Otra variedad son los llamados blogs de opinión, se trata de bitácoras enfocadas hacia el debate o discusión de opiniones o valoraciones. El autor busca dar a conocer su opinión sobre el tema y hacer circular esa información entre una, por norma general ya instaurada, red social de autores de blogs dentro de un mismo anillo o grupo. Suelen proporcionar información centrada en el usuario sobre tarifas, abusos, ofertas que puedan ser de interés para el consumidor o cualquier otra valoración realizada desde un punto de vista personal. Los blogs de noticias y novedades publican periódicamente curiosidades o noticias llamativas para su autor que pueden estar relacionados con el turismo y generalmente hacen referencia a la misma noticia o entrada que ya ha publicado otro sitio web, de manera que funcionan a modo de diario o recopilación de anuncios o avisos. Todos los modelos de bitácoras vistos hasta ahora podían tener un único autor o varios, pero dentro de los blogs grupales cabe destacar aquellos creados por comunidades de viajeros en un ejemplo que plasma fielmente la idea de conocimiento colectivo a la que se hacía referencia como pilar del modelo Turismo 2.0. En las bitácoras de comunidades de viajeros o blogs de viajes colaborativos, encontramos las opiniones y conocimiento, a través de descripciones, fotografías y vídeos de varios usuarios sobre los mismos destinos, con lo que ya no son opiniones y visiones particulares sino generalizadas. Representan quizás el aporte más fiable y completo de información sobre un destino turístico, al margen de intereses económicos o visiones muy particulares. Si bien, para participar de una de estas comunidades se debe obtener autorización por parte del administrador o administradores.

3. Formatos especiales. Como punto aparte cabe destacar que existen formatos especiales de bitácoras que dentro de cualquiera de las categorías anteriores podemos 
utilizar para presentar la información. Funcionan de manera análoga a cualquier otra bitácora pero difieren en la presentación del contenido, se trata de los Videoblogs o Videocast ${ }^{15}, \operatorname{los}$ Fotoblogs $^{16}$ y $\operatorname{los}$ Audioblogs o Podcast ${ }^{17}$. Están estructurados de la misma forma, pero el contenido de la entrada será en formato vídeo, imagen o archivo de sonido, respectivamente. Se trata de una especialización de las bitácoras para los contenidos, de forma que la mayoría de las entradas deben seguir el formato. Sería la diferencia entre subir un vídeo a un blog y un Videoblog, la entrada en formato vídeo o conteniendo vídeo debe ser predominante, por lo menos lo bastante para mantener una secuencia. Visto de una manera técnica cada uno de estos formatos de bitácora supone proveer de un almacén on-line para ese tipo de archivo. Si buscamos un gran número de fotografías ubicadas en un destino y no nos interesa andar leyendo descripciones, opiniones o valoraciones podemos optar por buscar un Fotoblog y navegar en sus archivos recopilando lo que necesitemos. Para el autor del Fotoblog éste es una herramienta que le permite ir almacenando las fotografías realizadas durante su viaje en Internet de manera que estén clasificadas por fecha, categorías y etiquetas tanto para realizar una copia de seguridad como para liberar la memoria del dispositivo con que fueron tomadas. El ejemplo de las fotografías será extensible a vídeo y audio. Si bien cabe destacar que el uso del formato Audioblog está más extendido en los países anglosajones como diario personal hablado o como guía de viaje, este formato podemos encontrarlo representado en mayor número de ocasiones como blog de opinión o programa de radio. Estos tres modelos de blog poseen también versiones como aplicaciones web 2.0, a través de servicios de gestión de archivos en cada formato, con un funcionamiento y estructura muy similar al de los blogs y ofreciendo las mismas funcionalidades aunque ampliadas por ser herramientas especializadas en dichos contenidos. Por último, pero dentro de estos formatos especiales, cabe mencionar los Mobileblogs o Moblogs ${ }^{18}$, que son bitácoras actualizadas vía mensajes multimedia desde teléfonos móviles. El autor del blog publica el contenido del mensaje como entrada corta, pudiendo adjuntar imágenes, audio o vídeo captados con el mismo dispositivo. Facilita al viajero la publicación por no requerir un ordenador con conexión a Internet y abarata los costes de sus comunicaciones.

4. Otras herramientas 2.0. Por último, decir que existen infinidad de herramientas de la Blogosfera pertenecientes al modelo Web 2.0 que tienen o podrían tener su aplicación en el ámbito turístico. Se podrían destacar los buscadores y directorios especializados en blogs ${ }^{19}$ y los marcadores sociales ${ }^{20}$, como herramientas que facilitan la recuperación de información. Los sistemas gestores de archivos multimedia ${ }^{21}$ para almacenamiento de imágenes, vídeos o sonidos. Sistemas orientados a promoción de productos

15 P. ej. MobuzzTV: http://mobuzztv.com.

16 P. ej. Fotoblog: http://fotoblog.com.

17 P. ej. Podcast-es: http://podcast-es.org.

18 P. ej. Moblog: http://moblog.co.uk.

19 P. ej. Technorati: http://technorati.com; Agregax: http://agregax.com.

20 P. ej. Del.icio.us: http://del.icio.us; Gennio: http://gennio.com.

21 P. ej. YouTube: http://youtube.com; TurnHere: http://turnhere.com; y un largo etcétera. 
y a su acercamiento a los usuarios $^{22}$, con clara orientación hacia el Social Media Marketing. Sistemas de localización geográfica ${ }^{23}$ y un largo etcétera. Por supuesto, existen blogs especializados en realizar recopilaciones de estas herramientas aplicables en el modelo de Turismo 2.0.

Figura 7. Visión de la Blogosfera restringida al ámbito del Turismo 2.0.

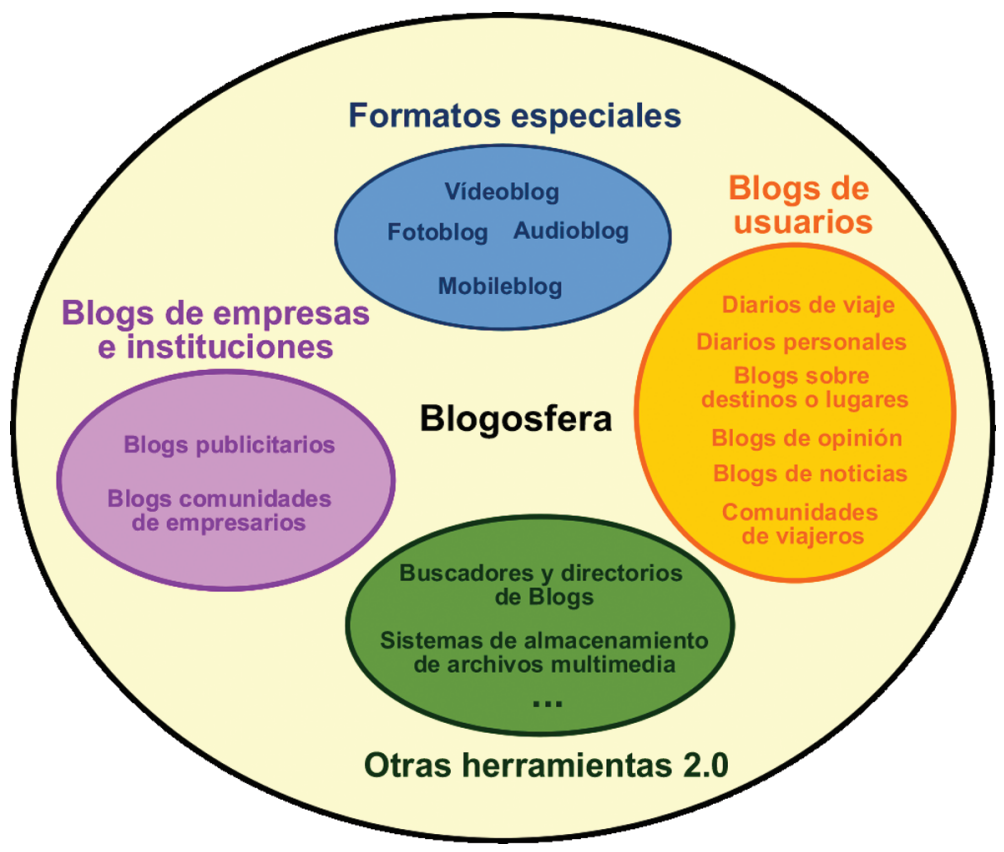

Fuente: Elaboración propia

\section{BIBLIOGRAFÍA}

Carpintier, Rodolfo (2003): "El cambio de comunicación en la empresa", Baquía, en: http://www.baquia.com/com/20031231/art00003.html

Celaya, Javier (2006): "Blogs y comunicación empresarial: escuchar la red”, COMUNICAS-Revista de tendencias en comunicación, 5: 20-21.

Celaya, Javier y Herrera, Pau (2007): Comunicación empresarial 2.0. La función de las nuevas tecnologías sociales en la estrategia de comunicación empresarial, Barcelona, Grupo BPMO, pp 97-101. 
Cobo Romaní, Cristóbal; Pardo Kuklinski, Hugo (2007): Planeta Web 2.0. Inteligencia colectiva o medios fast food. Grup de Recerca d'Interaccions Digitals, Universitat de Vic, Barcelona / México DF, Flacso México, pp. 61-85.

Dans, Enrique (2005): "Blogs y empresa. Una aproximación a la vanguardia de la blogosfera corporativa”, TELOS-Cuadernos de comunicación, tecnología y sociedad, 65: 78-85.

Forrester (2007): "Forrester report on Social Technographics", en Distributed Influence: Quantifying the Impact of Social Media, disponible en: http://technobabble2dot0.wordpress.com/social-media-white-paper/

Lew, Alan A. (2007): Web 2.0 Virtual Travel-escapes. Ponencia para "Association of American Geographers, 103th annual meeting”, San Francisco, 17-21 abril 2007, en: http://www.slideshare.net/alew/travel-20-the-emerging-web-20-virtual-travelscape

Novos Medios (2006): Grupo de Investigación de la Facultade de CC. da Comunicación /Universidade de Santiago de Compostela. Ponencia "A Blogosfera en galego: Demografía, Usos e Contidos”, presentada por Silvia Canabal, Manuel Gago, Xosé López, Antonio Isasi, Moisés Limia, José Pereira para: Enblogs'06. Encontro de Blogs entre Galicia e Portugal. Celebrada en Santiago de Compostela el 19 de abril de 2005.

O'Reilly, Tim (2005): What Is Web 2.0. Design Patterns and Business Models for the Next Generation of Software, en:

http:/www.oreillynet.com/pub/a/oreilly/tim/news/2005/09/30/what-is-web-20.html

O’Reilly, Tim (2006): Web 2.0 Compact Definition: Trying Again, en: http://radar.oreilly.com/archives/2006/12/web_20_compact.html

Technorati: Estadisticas propias del buscador de Blogs Technorati, en: http://www.technorati.com

William, Edu (2007): Turismopedia. Definición de Turismo 2.0, en: http://wiki.turismo20.com/doku.php 